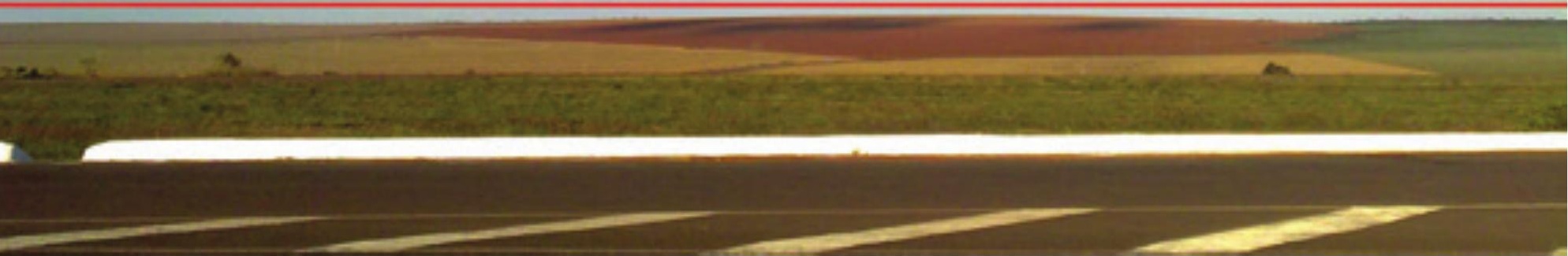




\title{
Desafios interculturais e educacionais para um turismo sustentável
}

\author{
Intercultural and educational challenges for sustainable tourism
}

\author{
Domira Fernandes de Araujo ${ }^{1}$ \\ Maria da Conceição Pereira Ramos²
}

\footnotetext{
1 Professora da Fundação Visconde de Cairu - FVC (Salvador-Bahia). Doutora em Turismo e Desenvolvimento Sustentável - Universidade de Las Palmas de Gran Canaria-ULPGC - Espanha. Mestre em Turismo - ULPGC. Licenciada em História - Universidade Católica de Salvador-BA - UCSal. Pós-doutorado na Faculdade de Economia-FEP/Universidade do Porto (UP)-PT, Área da Economia dos Recursos Humanos. E-mail: domira21@yahoo. com.br.

2 Professora da Faculdade de Economia (FEP) da Universidade do Porto (UP) - Portugal. Doutora em Ciência Econômica pela Universidade de Paris I - Sorbonne (França). Mestre em Economia dos Recursos Humanos pela Universidade de Paris I - Sorbonne. Licenciada em Economia pela Universidade de Coimbra - Portugal. Investigadora no Centro de Estudos das Migrações e das Relações Interculturais (CEMRI), Universidade Aberta (Portugal). E-mail: cramos@fep.up.pt.
} 


\section{Resumo}

Este artigo pretende fazer uma reflexão sobre os desafios interculturais e educacionais para um turismo sustentável, que favoreçam a integração de práticas educativas inclusivas. O intercultural implica relação, diálogo e comunicação entre as diferentes culturas, através dos indivíduos e grupos, na qual se encontram e interagem indivíduos, grupos e instituições originários de universos diferentes. Implica uma troca entre as diversas áreas do conhecimento, cujos olhares interdisciplinares sejam capazes de levar as organizações a desenvolverem propostas de educação voltadas para a inclusão, buscando interagir conceitos de interculturalidade, educação intercultural e turismo sustentável. Porém há uma lacuna de produções que visam explicitar a relação entre educação e turismo sustentável, elemento motivador deste estudo, realizando pesquisa bibliográfica nas bibliotecas da Fundação Visconde de Cairu e da Universidade do Porto. É importante o diálogo dessas relações, numa perspectiva de interdisciplinaridade e de sustentabilidade, fazendo com que a atividade turística seja geradora de efeitos positivos sobre as populações e economias locais, a proteção do ambiente, a preservação da cultura e tradição e a utilização racional de recursos naturais. Estas reflexões teóricas sinalizam para a necessidade de comunicação entre as diferentes culturas, em especial na educação e no turismo, com ênfase na interculturalidade, à luz da revisão da literatura sobre o assunto, na perspectiva de uma sociedade mais igualitária e sustentável.

Palavras-chave: Educação, turismo, interculturalidade, sustentabilidade.

\section{Abstract}

This article aims to reflect on intercultural and educational challenges for sustainable tourism that fosters the integration of educational and inclusive practices promoted when human relationships become harmonious and cooperative. Intercultural implies relationship, dialogue and communication between different cultures, across individuals and cultures possess these groups, which meet and interact with individuals, groups and institutions from different universes. Also involves an exchange between different areas of knowledge whose interdisciplinary looks to be able to lead organizations to develop proposals aimed at education inclusion, seeking concepts interact intercultural, intercultural education and sustainable tourism. Therefore there is a lack in researches that seek to make a relation between education and sustainable tourism, the reason of this study, in which we performed a bibliographic research in Visconde de Cairu Foundation and Porto University Libraries. Dialogue is important these relationships from the perspective of interdisciplinarity and sustainability, making the tourism industry is generating positive effects on local populations and economies, environmental protection, preservation of culture and tradition and the rational use of natural resources. These theoretical considerations point to the need for communication between different cultures, especially in education and tourism, with emphasis on interculturalism, in light of the literature on the subject, in view of a more equitable and sustainable society.

Keywords: Feducation, tourism, intercultural, sustainability. 


\section{Introdução}

A internacionalização da educação e a interculturalidade têm sido objeto de diversas pesquisas, produções e publicações científicas, decorrentes das mais diversas áreas do conhecimento, como educação, cultura, cidadania, comunicação, meio ambiente, identidade, relacionadas ao mundo das viagens, colocando-os dentre os desafios para a garantia de um turismo sustentável.

Conforme observaram Alsina (1999) e Ramos (2007), os especialistas concordam que o incremento dos movimentos migratórios é cada vez maior, e que as facilidades dos transportes e comunicações favorecem os contatos das pessoas por intercâmbios culturais, a exemplo do turismo, entre outros. Neste contexto, o processo de globalização da economia, da tecnologia e da comunicação tem mostrado não só a necessidade de comunicação entre diferentes culturas, mas entre as diversas áreas do conhecimento.

Considerando o turismo uma atividade que se apresenta como importante dimensão das modernas mobilidades contemporâneas, uma análise multidisciplinar contribui no entendimento dessa questão, tendo em vista o fenômeno da globalização e seu reflexo na interculturalidade. Bauman (2003) ao considerar o turismo como um eixo de representação da sociedade contemporânea faz uma distinção entre o turismo como metáfora para a vida contemporânea e o turismo como importante exemplo de atividade.

Relativo ao turismo ou turistas como metáforas, o autor refere-se a aspectos da condição do turista em termos da experiência, que implica estar em algum lugar, condições que ocorrem ao mesmo tempo em que as pessoas estão inseridas na companhia de outras, todos os dias, no seu cotidiano, nos lugares em que se vive ou se trabalha, cuja característica da vida contemporânea, Bauman (2003) chama de "tourist syndrome".

Na visão de Urry (1996), e outros sociólogos, a mobilidade contemporânea também está relacionada às questões de reflexividade, sendo possível refletir, a partir de algumas perspectivas teóricas, sobre a mobilidade no turismo e suas dinâmicas globais. É nesse contexto que autores como Urry (1996) referem-se a um paradigma da mobilidade, como proposta para novas análises sobre os novos cenários com os quais nos defrontamos. Esses processos de mobilidade têm proporcionado avanços importantes, que os transformam qualitativamente e quantitativamente, justificando que se fale de "hiper-mobilidades" (HUDSON, 2004).

Esse cenário de mundialização promoveu o crescimento das tecnologias, dos meios de comunicação, das redes sociais, incorporadas ao campo da educação, que se ex- 
pressa pelas políticas e práticas dos sistemas acadêmicos e das instituições de ensino, com o objetivo de enfrentar este ambiente globalizado, o que possibilita uma maior interação da coletividade educacional. Isto porque estas relações não se estabelecem de forma harmônica, conforme mencionam Sogayar e Rejowski (2011, p.283):

Esse processo de interação no plano mundial, entretanto, não ocorre sem resistência, tendo origem nas questões da territorialidade e nos modos como ocorre o processo de socialização. Assim se reflete nas formas e processos educacionais em diferentes contextos culturais, marcando diferenças que podem ocasionar, por vezes, desentendimentos e hostilidades, não raro desencadeando situações de conflito e violência.

Portanto, no mundo atual, a necessidade de comunicação entre diferentes culturas se intensifica à medida que nos deparamos com conflitos e interações sociais cada vez mais complexos, assim é que a educação e a interculturalidade estão relacionadas, no sentido de atender a essa pluralidade.

Realidade esta, que exige ver o mundo com outros olhos, ou seja, é descobrir o outro diferente, saber que não pensamos todos da mesma maneira e que não gostamos todos das mesmas coisas, criando a partir daí, pontes para nos entendermos melhor, como destaca Duque (2005). Nesse sentido, pesquisas recentes em educação consideram essa perspectiva e falam em ensino de forma intercultural, dentre as quais destacamos os estudos de Ramos (2009), ao afirma que:

O intercultural implica relação, diálogo e comunicação entre as diferentes culturas, através dos indivíduos e grupos portadores dessas culturas, em situações interculturais diversas, ou seja, em situações, na qual se encontram e interagem indivíduos, grupos e instituições originários de universos culturais diferentes (RAMOS, 2009, p.19).

É urgente, pois, segundo esta autora, educar para a interculturalidade e cidadania (RAMOS, 2011). Compreensão esta que também se encontra traduzida nas palavras de Jacobi $(2003$, p. 5):

A educação para a cidadania representa a possibilidade de motivar e sensibilizar as pessoas para transformar as diversas formas de participação em potenciais caminhos de dinamização da sociedade e de concretização de uma proposta de sociabilidade baseada na educação para a participação.

Nesta mesma perspectiva, Walesko (2006) considera que o contato permanente com outros povos e culturas, facilitado pelo enorme avanço dos meios de transporte e comunicação, exigem que a educação se volte à formação de cidadãos com acesso à diversidade cultural, seja ela de línguas estrangeiras, ou de qualquer outro conteúdo escolar que caracteriza todo o processo de ensino/aprendizagem. 
Aprender é antes de tudo, estar incluído e participar na criação, não só de produtos da cultura como também de processos sociais, de criação dessa cultura, de processos que conduzem a uma mudança na qualidade do compromisso, da participação, do respeito ao pensamento distante, de sentimentos de solidariedade (BRANDÃO, 1986, p.5, apud BARTOLOMÉ, 2000, p.131).

E, para Freire (1983), aprender implica, antes de mais, nas palavras de "aprender a ler o mundo", ou seja, adquirir instrumentos para conhecer e interpretar o que se passa à nossa volta e agir de forma autônoma e coerente.

Entretanto, apesar do reconhecimento da necessidade de uma educação intercultural e para a cidadania, e de haver uma crescente demanda turística no Brasil, ainda há uma carência de produções que visem explicitar a intrínseca relação entre educação e turismo sustentável, quer de forma assistemática no âmbito da sociedade como um todo, quer nas escolas de educação básica e nas instituições de ensino superior. Motivo pelo qual nos voltamos para esta temática, realizando pesquisa bibliográfica nas bibliotecas da Fundação Visconde de Cairu e da Universidade do Porto.

Para tanto, este artigo apresenta algumas reflexões teóricas sobre a questão da interculturalidade relacionada à educação e ao turismo, no âmbito de um mundo globalizado, na perspectiva de dialogar com as diferentes áreas do conhecimento, ancorada nos autores que balizam a referida questão, sinalizando para a necessidade de comunicações entre diferentes culturas, em especial na educação e no turismo, com principal realce à interculturalidade como uma dimensão a ser desenvolvida durante o processo de formação humana e profissional de diversas áreas, notadamente a de turismo. Visamos, assim, contribuir para dar visibilidade a este aspecto para que seja mais amplamente discutido.

Este artigo contempla três partes, em que a primeira aborda, de modo geral, a interculturalidade relacionada à educação, à luz dos conceitos da literatura sobre o assunto. Em seguida, estabelece um diálogo entre educação e cultura, na perspectiva de uma educação plural. Na terceira parte expõe sobre o turismo sustentável e sua dimensão intercultural, e finaliza com algumas considerações sobre a educação entre as diferentes culturas e a cidadania intercultural como pressuposto para uma sociedade mais igualitária e sustentável.

\section{Educação e interculturalidade}

A interculturalidade implica nas noções de reciprocidade e troca na aprendizagem, na comunicação e nas relações humanas. Ela se faz a partir do momento em que 
há uma preocupação de comunicação entre os indivíduos portadores de diferentes culturas, estabelecendo um intercâmbio entre pessoas, para a construção de conhecimentos, saberes e práticas culturalmente diferentes, buscando desenvolver um novo sentido entre elas. Isto implica em reestruturar o sistema de atitudes, no qual cada um de nós é responsável pelas representações que temos dos outros, indo mais além, como bem explicitam as palavras de Carvalho e Carvalho (2008, p. 157):

O princípio da interculturalidade não implica em simplesmente reconhecer o valor de cada uma dessas culturas e defender o respeito entre elas. Mais que isso, a interculturalidade apresenta-se como um princípio que fornece elementos consistentes que permitem provocar o desvelamento, o enfrentamento e a posterior busca de soluções para os conflitos desse relacionamento, em todas as suas dimensões.

Neste sentido, no ano de 2006, a UNESCO produziu e editou um Guia de Educação Intercultural, que recolhe as melhores práticas em matéria de formação e consolida uma considerável reflexão teórica de suporte. Tal preocupação reflete a atenção crescente, devotada à relação estreita entre cultura e educação, que encontrou pleno acolhimento no "Compromisso de Rabat" sobre o Diálogo de Culturas e Civilizações.

Dando continuidade a ações nesta vertente e reconhecendo o valor da diversidade cultural e interculturalidade em educação superior, a UNESCO (2008) desenvolve um projeto de investigação sobre experiências de Instituições Educativas (IES) da America Latina dedicadas a atender necessidades e demandas de formação de comunidades indígenas e afro descendentes; assim como formular recomendações políticas com relação à educação superior, com observações entre este campo e outros temas de grande importância regional, como a inclusão social, a ciência e a tecnologia no desenvolvimento sustentável.

Para Araújo (2010), as pesquisas recentes em educação e turismo, consideram essa perspectiva e incorporam o Ensino Intercultural, a Pedagogia Intercultural e a Educação Intercultural para o um desenvolvimento humano mais harmonioso.

Segundo Carneiro (2008), a educação intercultural será orientada no sentido do pleno desenvolvimento da personalidade humana e do fortalecimento do respeito pelos direitos humanos e pelas liberdades fundamentais. A educação intercultural promoverá a compreensão, a tolerância e a amizade entre todas as nações e grupos raciais ou religiosos, e coadjuvará as atividades das Nações Unidas em prol da manutenção da paz.

Portanto, aceitar o princípio da interculturalidade significa prestar atenção à nossa prática diária e combatermos todas as atitudes discriminatórias no contacto com a diferença, seja ela de nível cultural, de aspecto físico, de nacionalidade, de religião. 
É o momento para fomentar mudanças na formação intercultural que se oferece nos centros de formação, uma vez que os mesmos deverão se preparar para novas situações decorrentes do contexto mundial, sobre o qual já discorremos.

Para conseguir este objetivo, os centros de formação deverão dar especial atenção à formação do professorado, com o fim de sensibilizar os docentes para as novas realidades sociais, considerando que a necessidade de integração de pessoas e cultura de forma integral e global requer habilidade e flexibilidade, entendendo que a educação intercultural deve atuar como promotora e dinamizadora de uma sociedade que eduque e de uma educação que integre, uma vez, que mediante a educação, dificuldades e conflitos poderão ser evitados, ou minimizados (LLAMAS, 2005).

Educar para a cidadania é desenvolver a capacidade de compreensão e intervenção no relacionamento com outras culturas e espaços e ter subjacentes valores democráticos de participação, solidariedade e responsabilidade. Mas se a educação constitui um campo estratégico fundamental para o desenvolvimento das práticas de cidadania, a educação para a cidadania não diz respeito, exclusivamente, ao domínio escolar, mas também à vida social como um todo, ou seja, é um trabalho contínuo que se opera nas mais diversas áreas da sociedade, transcendendo o espaço físico da escola, como destaca Ramos M. (2003, p. 262):

É preciso garantir a formação em termos de valores cidadania, conhecimentos científicos e preparação para o mercado de trabalho. Também a colaboração entre escolas, empresas e famílias poderá conduzir à formação para a cidadania, conhecimento e empregabilidade.

Segundo Guimarães (2011), podemos perceber uma rede complexa de questões presentes na sociedade atual, que devem ser problematizadas sob o olhar de diferentes ciências, como a sociologia, economia, antropologia, história, geografia, psicologia, que buscam levar as questões da equidade, da igualdade de direitos, a um foro de discussão interdisciplinar e intercultural, o que demanda abertura ao diálogo numa perspectiva intercultural.

\section{Diálogo e comunicação intercultural}

O diálogo intercultural requer o empoderamento de todos os participantes por meio da capacitação e de projetos que divulguem a interação sem a perda da identidade pessoal ou coletiva (UNESCO, 2009, p.12).

A Educação Intercultural, enquanto instrumento nos ajuda a situar e a intervir no mundo que nos rodeia, e se inscreve numa perspectiva mais ampla, a educação para a cidadania, na qual a coesão social aparece associada à valorização da diversidade, 
visto que, "No plano das representações sociais ou ideológicas, a interculturalidade surge como uma nova visão do homem" (RAMOS, M., 2003, p. 262).

Para isso há que pensarmos numa educação plural, o que implica reestruturar o conjunto de atitudes que em cada um de nós é responsável pelas representações que temos dos outros. Toda a rua, bairro, cidade ou país, possui sua identidade, uma bagagem cultural e histórica que os moradores da localidade criaram com o passar dos tempos. Esta identidade é muito particular e é capaz da atrair a simpatia dos visitantes justamente por se sentirem dentro do contexto histórico do lugar e conhecerem, conviverem e desfrutarem de hábitos de uma cultura totalmente diferente da sua. Proposição que se encontra ratificada nas palavras de Vieira (199, p.2):

\begin{abstract}
Quando utilizo o conceito de intercultural, faço-o justamente a partir do momento em que há uma preocupação de comunicação entre os indivíduos portadores de diferentes culturas. Para isso há que pensar numa educação para o plural, o que implica reestruturar o sistema de atitudes que em cada um de nós é responsável pelas representações que temos dos outros - quer dizer, metamorfosear a identidade pessoal.
\end{abstract}

Com o turismo, sobretudo para as cidades, e com a migração que ocorre essencialmente do campo para os meios urbanos, registra-se um aumento de contactos entre as culturas, colocando desafios à gestão da diversidade cultural, à comunicação intercultural e ao planeamento urbano (RAMOS, 2008). As diásporas resultam da dispersão das populações e culturas no tempo e no espaço e têm implicações no consumo, na produção e nas práticas de turismo para diferentes grupos culturais e espaços geográficos (COLES; TIMOTHY, 2004).

Segundo Ramos $(2007,2009,2011)$ e Carneiro (2008), educar para a interculturalidade consiste também em educar os olhares sobre o mundo e aprender a apreciar substantivamente o próximo ou semelhante. Dito de outro modo, é conquistar para a descoberta do outro, pelo exercício sistemático da escuta e pela procura do sentido do universal que pode habitar no diferente.

Significa, pois, adotar a perspectiva do intercultural como processo de diálogo, comunicação entre pessoas ou grupos pertencentes a culturas diferentes (nacionalidades, origem social, gênero, ocupação, etc.), que promove a integração e o respeito à diversidade e permite ao educando encontrar-se com a cultura do outro sem deixar de lado a sua própria, ou seja, incentiva o respeito a outras culturas, a superação de preconceitos culturais e do etnocentrismo. "Assim sendo, ao trabalhar em uma perspectiva intercultural, o educador estará contribuindo para a construção de uma visão do mundo, de uma leitura da realidade consciente da pluralidade social e cultural de nosso contexto atual" (WALESKO, 2006, p.27). 
O diálogo entre cultura e educação é inesgotável. A cultura determina o contexto, os quadros de referência, as crenças e os modos de valorar a educação, ao mesmo tempo em que é também por eles determinada. Por seu turno, a educação é a condição de sobrevivência, de enriquecimento e de transformação da cultura. Entre as pessoas com diferentes culturas, o diálogo pode estreitar os laços de amizade, aprofundar o conhecimento libertando uma série de preconceitos, e no caso do turismo, controlado por uma indústria interessada em prover a satisfação entre visitantes e visitados, ameniza o choque cultural, podendo, em escala global, promover o crescimento da oferta e do fluxo turístico e atenuar as diferenças culturais, pois são justamente estas diferenças que muitas vezes atraem o visitante.

Estudos recentes, desenvolvidos pelas instâncias acadêmicas e pelas agências de desenvolvimento, são indicativos quanto à impossibilidade de progresso sem cultura, quanto ao imperativo de associar criação de riqueza com coesão social e confiança entre as pessoas. A esse paradigma sucede outro que é o do desafio do desenvolvimento sustentável com multicultura e diversidade, tendo em vista que:

As pessoas não valem apenas por si, individualmente, senão pela sua integração em comunidades fortes, eficientes e produtivas. Pessoas propensas ao diálogo com base no que descobrem, permanentemente, do que têm em comum com as outras. Pessoas que não temem pensar por si e sentir com as outras. Pessoas que lutam contra a fatalidade do confronto predatório de identidades (CARNEIRO, 2008, p. 34).

Para Walesko (2006), ao citar Santos (2004), a interculturalidade compreende atitudes comprometidas com princípios orientados para o respeito ao outro, às diferenças, à diversidade cultural, que caracteriza todo o processo de ensino/aprendizagem, seja ele de línguas ou de qualquer outro conteúdo escolar, na tentativa de promover a interação, a integração e cooperação entre os indivíduos de diferentes mundos culturais.

\section{Turismo sustentável e interculturalidade}

Podemos dizer que o mundo de hoje tende a ser um mundo intercultural e o turismo tem ajudado esta aproximação das pessoas e dos povos. As viagens, por exemplo, podem ser entendidas como um encontro com o outro. Esta idéia expressa à necessidade de crescermos, confrontando as nossas maneiras de ser e de estar no mundo e experimentar outras vivências num processo dinâmico de troca (ARAUJO, 2013).

As experiências de viagens implicam aceitação das diferenças e da diversidade, 
entendido aqui, a partir de um olhar que valorize as redes de relações socioculturais estabelecidas em seus espaços. As conceituações elaboradas por Banducci e Barretto (2001) e Moesch (2002) revelam-se mais adequadas. Estes autores tratam o turismo como "fenômeno social" por ser uma "combinação complexa de inter-relacionamento" (MOESCH, 2002, p. 9). O turismo passou a ser a forma mais procurada de lazer e, na atualidade, fazer turismo tornou-se uma aspiração de todos os incluídos na sociedade global de consumo (BANDUCCI e BARRETTO, 2001).

Barreto (2003) realiza quase que uma "crônica" dos estudos de antropologia aplicada ao turismo e constata que a maior parte desses estudos têm focalizado, em especial, os impactos nas culturas receptoras, os processos de aculturação e as questões de autenticidade, requerendo programas e ações em que interajam indivíduos, grupos e instituições com o universo local, na perspectiva de um desenvolvimento sustentável.

O debate sobre a sustentabilidade do turismo foi influenciado pela evolução do conceito de desenvolvimento sustentável, apontando para o fato de que é preciso considerar apropriadamente o bem-estar econômico, ambiental, sociocultural e político de longo prazo (RAMOS, M., 2012 a,b). O turismo sustentável é definido pela Organização Mundial do Turismo - OMT (2003) como aquele que é ecologicamente sustentável no longo prazo, economicamente viável, assim como ética e socialmente equitativo para as comunidades locais, propiciando um desenvolvimento sustentável. Os esforços recentes de desenvolvimento e de turismo vêm reconhecendo os desafios atuais relacionados às questões ambientais, sociais, econômicas e ecológicas, visando também ações responsáveis na busca da sustentabilidade local.

A perspectiva do desenvolvimento local acontece quando as pessoas envolvidas são beneficiadas em seus territórios. Portanto, a noção de turismo sustentável deve levar em conta um modelo de desenvolvimento econômico que permita melhorar a qualidade de vida das comunidades anfitriãs; melhorar a qualidade de vida com benefícios económicos e sociais não só para os residentes, mas também para as empresas. "Temos a viabilidade política e econômica, mas o econômico é apenas o instrumental - o social é o mais importante" (SACHS, 2002, p.1).

É importante manter a qualidade do ambiente da qual depende não só a comunidade anfitriã, mas também o visitante, buscando assegurar uma distribuição equitativa tanto dos benefícios como dos custos, e encorajar a compreensão dos impactos do turismo no ambiente cultural, humano e material no sentido de promover uma qualidade na experiência do visitante (MARUJO e CARVALHO, 2010, p.3).

Podemos vislumbrar, a partir da percepção das relações interpessoais proporcionadas pela atividade turística os diversos aspectos que podem ser abordados pela 
antropologia. Ramos e Figueiredo (2009), afirmam que somente há pouco mais de meio século, pesquisadores da área de Ciências Sociais mostraram-se motivados a estudar o turismo, o que para Barreto (2003) é um paradoxo.

É importante destacar, programas como o Observatório do Desenvolvimento Humano (PODH) 3 que objetiva consolidar a integração entre ensino, pesquisa e extensão, através de uma experiência acadêmica que visa o desenvolvimento humano, levando o Mestrado de Desenvolvimento Humano e Responsabilidade Social - MDHRS da Fundação Visconde de Cairu a cumprir o seu papel social como organização do terceiro setor, desenvolvendo um projeto piloto na llha de Maré4, não apenas nas questões infraestruturais, mas buscando uma participação política e social por parte da população.

Considerada como uma das regiões mais pobres da capital baiana, a llha de Maré apresenta carências especiais nas áreas de saúde, educação, transporte e segurança pública. Entretanto, esta ilha desperta o interesse dos visitantes pelo grande potencial humano, notáveis na culinária e na produção artesanal, sem contar os muitos atrativos naturais que a fazem uma das mais concorridas paragens nos passeios marítimos pela Baía de Todos os Santos, tendo no turismo, uma importante atividade estratégica local, principalmente no que se refere ao seu patrimônio cultural e natural. Debatem-se, atualmente, os impactos econômicos, socioculturais, ambientais e locais do "turismo sustentável" e atividades relacionadas, como a agricultura e a pesca (RAMOS, N., 2012).

Conforme Araujo (2011), o turismo tem registrado, sobretudo para as cidades, um aumento sem precedentes de contatos entre as culturas, colocando importantes desafios à formação e qualificação dos recursos humanos nessa área. Tratando-se de educação em turismo, é reconhecida a sua relevância, ainda que não seja tão destacada, como em outras esferas do conhecimento, por ser esta formação superior, relativamente recente (ARAUJO, 2012, p. 296).

Utilizar as ferramentas adequadas e desenvolver o turismo em uma localidade é estimular o turismo sustentável, capaz de minimizar os impactos, estabelecer a comunicação e ainda movimentar a economia do local.

Há que promover o turismo sustentável e o eco-negócio de diversas formas, respeitando a herança cultural, os recursos naturais, os modos de vida e o desenvolvimento econômico e mantendo, ao mesmo

3 Programa do Mestrado de Desenvolvimento Humano e Responsabilidade Social- MDHRS, com base nos Objetivos de Desenvolvimento do Milênio (ODM) do Programa das Nações Unidas para o Desenvolvimento (PNUD). 4 Localizada na Baía de Todos os Santos, a maior Baía do Brasil e segunda maior do mundo, um distrito isolado de Salvador-BA. 
tempo, a coesão social e a sua identidade. No turismo, a adaptação às mudanças climáticas modifica a forma de viajar das pessoas, podendo afectar o emprego neste sector (RAMOS. M., 2012a, p. 34).

$E$, muitas vezes, é essa identidade que provoca a interação entre o turista e o meio receptivo e o fruto desta interação é a troca de experiências que muitos turistas procuram nessa abertura de fronteiras, para a entrada de novas culturas, o que é bom tanto cultural como economicamente. A realidade atual exige uma reflexão cada vez menos linear, e isto se produz na inter-relação entre saberes e práticas coletivas, que criam identidades e valores comuns, e ações solidárias, face à reapropriação da natureza, numa perspectiva que privilegia o diálogo entre saberes (JACOBI, 2003, p.3).

O papel que o fenômeno turístico exerce para com a humanidade é objeto de estudo em diversas áreas do conhecimento cientifico. Segundo Gastal (2005), a comunicação intercultural e interpessoal, pode facilitar a aproximação entre as pessoas de culturas diferentes para o turismo, assim como para a sociedade, tanto como a compreensão e o respeito das diversas culturas através do diálogo entre o visitante e o visitado. Porém, conhecer os resultados desta interação entre os povos e garantir categoricamente a influência do turismo para a paz mundial é uma visão bastante positiva, messiânica e quem sabe ilusória para muitos.

Tal reflexão perpassa, obviamente, por questões singulares como a cidadania, o ambiente, a ética, a sustentabilidade e a necessidade de inclusão social, pois estas e outras questões relacionadas ao desenvolvimento do turismo sustentável não são exclusivas do setor público, mas de toda a sociedade. Sendo assim, as instituições de ensino superior também devem tratar dessas questões em suas salas de aula (PANOSSO NETTO e TRIGO, 2003).

Compreender a atividade turística é, aparentemente, uma tarefa um pouco mais simples do que o seu impacto para a humanidade, na medida em que a sua força econômica contribui para uma melhor distribuição de renda, por meio da geração de trabalho e emprego, além de atuar como facilitador da paz internacional. Sendo assim, a comunicação interpessoal proporcionada pelo turismo, pode ser útil à realização da paz entre os povos.

\section{Considerações finais}

Ao trazermos algumas reflexões teóricas sobre a questão da interculturalidade relacionada à educação e ao turismo, no âmbito de um mundo globalizado, sinalizamos para a necessidade de reconhecermos a interculturalidade como uma dimensão a ser 
desenvolvida durante o processo de formação humana e profissional de diversas áreas. Portanto, evidenciamos a necessidade de que os estabelecimentos de ensino elaborem uma política sistemática de formação permanente no domínio do ambiente e do turismo. Nesse sentido, a produção de conhecimento deverá necessariamente contemplar as inter-relações do meio natural com o social, incluindo a análise dos determinantes do processo.

Diante dos desafios esperados pelo futuro, a educação estruturada numa perspectiva de cidadania e interculturalidade surge como um triunfo indispensável, para que a humanidade tenha a possibilidade de progredir na consolidação dos ideais da paz, da liberdade e da justiça social.

Tal assertiva parte da compreensão do papel essencial da educação para o desenvolvimento contínuo das pessoas e das sociedades: não como um remédio milagroso, menos ainda como de um mundo que tivesse realizado todos os seus ideais, mas como uma via - certamente, entre outros caminhos, embora mais eficaz - ao serviço de um desenvolvimento humano mais harmonioso e autêntico, de modo a contribuir para a diminuição da pobreza, da exclusão social, das incompreensões, das opressões e das guerras, como propugnado pela UNESCO.

Surge, dessa maneira, um novo desafio, agora posto para as próprias instituições de ensino, qual seja: que proposta político-pedagógica deve nortear a instituição capaz de construir currículos e práticas pedagógicas que sustentem as tensões e os conflitos entre as culturas para que a diferença seja respeitada?

Desafio que exige principalmente das universidades repensarem as suas metodologias de ensino, superando a fragmentação e questionando o saber academicamente sedimentado, que perpassa e está subjacente em nossas práticas pedagógicas, objetivando o exercício constante da interculturalidade. $E$, no que tange a formação do profissional do turismo, cabe destacar que as percepções das problemáticas ambientais e turísticas geram demandas diferenciadas de conhecimentos teóricos e práticos.

Por isso, as propostas de educação superior, a exemplo da educação fundamental e média, devem caracterizar-se pela flexibilidade e permeabilidade, abrindo espaço para a pesquisa e a interculturalidade, permitindo uma educação para o turismo fundamentada nos princípios de sustentabilidade, e em um equilíbrio adequado entre as dimensões ambientais, socioculturais e econômicas do desenvolvimento turístico.

Estas reflexões que trazemos no presente artigo visam fomentar outras vias de entendimento da temática e sua inserção nos debates da área, visto que ainda carece de sua ampliação. 


\section{Referências}

ALSINA, M.R. Comunicación Intercultural. Ed. Anthopos. Barcelona, 1999.

ARAUJO, D.F. Educação Superior, Turismo e Interculturalidade: um novo olhar da educação para uma nova cultura. Perspectivas de educação ambiental no constructo da interculturalidade/Org. ARAÚJO, M.I.O. Aracaju: Ed. Criação, 2013, p. 37-50

ARAUJO, D.F. Inserción del profesional con formación superior en turismo en el mercado laboral. Polo turístico Salvador e Entorno Bahia, Brasil. Investigaciones sobre docencia universitaria y nuevas metodologías. Ourense. Educación Editora. 2012, p. 295-299.

ARAUJO, D.F. Formación Profesional en Turismo e Inserción en el Mercado Laboral: Un estudio de caso del Polo Turístico Salvador/Bahia, Brasil y su Entorno. Estudios e Perspectivas en Turismo - Revista CIET. Vol. 20, no 1, p. 57-74, , 2011, Buenos Aires.

ARAÚJO, P.C.A. Educação Intercultural: encontro entre culturas, diálogo de saberes. Secretaria de Educação Continuada, Alfabetização e Diversidade do Ministério da Educação (SECAD/MEC) Vitória-ES, 2010.

ARAÚJO, S. E. A. Educação para a Cidadania - Professores e Alunos em Contexto Intercultural, Lisboa: ACIDI, col. Teses, no 17, 2008, p. 11-14. (http://www.acidi.gov.pt). BANDUCCI, Jr. BARRETTO. M. (Org.). Turismo e identidade local: uma visão antropológica. Campinas: Papirus, Coleção Turismo, 2001.

BARRETO, M. O imprescindível aporte das ciências sociais para o planejamento e a compreensão do turismo. Horizontes Antropológicos.Vol.9, n. 20. p. 15-29, 2003.

BARTOLOMÉ, P.M. (Coord.) Identidad y Ciudadanía: Un reto a la educación intercultural. 2a . Ed. Narcea, S.A. de Ediciones. Madrid, 2008.

BARTOLOMÉ, P.M.; CABRERA, F. Sociedad multicultural y ciudadanía: hacia una 86 sociedad y ciudadanía intercultural: In: Revista de Educación, no extraordinario, p. 33-56, 2003.

BAUMAN. Z. Tourist Studies. London, v 3 (2), p. 205-217, 2003.

CARNEIRO. R. Educação Intercultural. Colecção Portugal Intercultural. Estudos Históricos sobre o Intercâmbio de Povos e Culturas. Volume IV - Desafios à Identidade. Lisboa: Alto Comissariado para a Imigração e Diálogo Intercultural, 2008.

Disponível: http://www.oi.acidi.gov.pt/modules.php?name=Content\&pa=showpage\&pid=44 Acesso em: 09 nov. 2012. 
CARVALHO, F. \& CARVALHO, F.A. A Experiência de Formação de Professores Indígenas do Núcleo Insikiran da Universidade Federal de Roraima. In: MATO, Daniel (coord.) Diversidad Cultural e interculturalidad en educacíon superior. Experiencias en America Latina y el Caribe (IESALC). Caracas: Instituto Internacional de la UNESCO para la Educación Superior en América Latina y el Caribe (UNESCO-IESALC), 2008, p. 157-166. http://ensinosuperiorindigena.wordpress.com/cosmologia/interculturalismo/. Acesso em: 15 de Ago. 2013

CARVALHO \& CARVALHO, 2008. Abrindo a caixa-preta do Multiculturalismo: a Interculturalidade. http://ensinosuperiorindigena.wordpress.com/cosmologia/interculturalismo. Acesso em: 13 de Out. 2013

COLES, T.; TIMOTHY, D. J. (Eds). Tourism, Diasporas and Space. London: Routledge, 2004. FREIRE, P. Pedagogia do Oprimido, Rio de Janeiro: Paz e Terra, 1983.

GASTAL, S. Turismo, imagens e imaginários. Série/Coleção: ABC do Turismo, 1ạ. Edição. Editora Aleph, São Paulo, 2005.

GUIMARÃES, V. Globalização e mobilidade: As condições de mobilidade contemporânea e as práticas turísticas. Revista Contemporânea, Vol.9, №2, p. 9-20, 2011. Disponível: www.contemporanea.uerj.br. Acesso em: 09 nov. 2012.

DUQUE, B. Um livro... Uma história... Interculturais. Editor: Alto Comissariado para a Imigração e Minorias Étnicas. Gabinete de Educação e Formação do ACIME/Entreculturas. Lisboa, Julho de 2005.

Disponível: http://ec.europa.eu/culture/documents/um_livro_uma_historia_portugal.pdf Acesso em: 10 dez. 2011.

HUDSON, R. Thinking through the geographies of the New Europe in the New Millennium, European Urban and Regional Studies, 11(2), p. 99-102, 2004.

JACOBI, P. Educação Ambiental, Cidadania e Sustentabilidade. Cadernos de Pesquisa da Fundação Carlos Chagas, vol. 118, São Paulo-SP, 2003, p. 1-19.

LLAMAS, J.G. Educación Intercultural: Análisis y Propuestas. Universidad Nacional de Educación a Distancia (UNED). Revista de Educación, no 336, p. 89-109, 2005.

MARUJO, M. N; CARVALHO, P. Turismo, planeamento e desenvolvimento sustentável. Turismo \& Sociedade, Curitiba, v. 3, n. 2, p. 147-161, outubro de 2010.

MOESCH, M. A produção do saber turístico. São Paulo: Contexto, 2002.

NASCIMENTO, A. C. Populações Indígenas, Universidade e Diferença. In: Anais da ANPED - Centro Oeste. Cuiabá, 2006. 
NEIMAN, Z. (Org). Meio ambiente, educação e ecoturismo. Baureri, SP: Manole, 2002. ORGANIZAÇÃO MUNDIAL DE TURISMO. Guia de desenvolvimento do turismo sustentável. Tradução de Sandra Netz. Porto Alegre: Bookman, 2003.

PANOSSO NETO, A.; TRIGO, L. G. G. Refexões sobre um novo turismo: política, ciência e sociedade. São Paulo: Aleph, 2003.

RAMOS, M. C. P. Ambiente, Educação e Interculturalidade. Revista Tempos e Espaços em Educação, Universidade Federal de Sergipe (UFS), no 8, p. 27-39, Janeiro/ Julho 2012a.

RAMOS, M. C. P. Educação ambiental, empregos verdes e sustentabilidade. In Serafim, J. F.; Santana, S. R. Lima de (Orgs.) Representações do Meio Ambiente - Clima, Cultura, Cinema. Salvador: EDUFBA, 2012b, p. 15-36.

RAMOS, M.C.P. Acção Social na Área do Emprego e da Formação Profissional. Lisboa: Universidade Aberta, 2003.

RAMOS, N. Espaços e tempo (s) das culturas do mar: perspectivas e desafios sociais, interculturais e de saúde. In Serafim, J. F.; Santana, S. R. Lima de (Orgs.) Representações do Meio Ambiente - Clima, Cultura, Cinema. Salvador: EDUFBA, 2012, p. 87-107.

RAMOS, N. Educar para a interculturalidade e cidadania. Princípios e desafios. In ALCOFORADO, L. et al. Educação e formação de adultos. Políticas, práticas e investigação. Coimbra: Imprensa da Universidade de Coimbra, 2011, p. 189-200.

RAMOS. N. Diversidade cultural, educação e comunicação intercultural - políticas e estratégias para a promoção do diálogo intercultural. Revista Educação em Questão. V. 34, n. 20, jan./abr, p. 9-32, 2009. Disponível: www.revistaeduquestao.educ. ufrn.br. Acesso em: 10 ago. 2011.

RAMOS, N. A diversidade cultural da cidade : problemas e desafios. In RUBIM, L; MIRANDA, N. (Orgs.). Transversalidades da cultura. Salvador: EDUFBA, 2008, p. 133-179. RAMOS, N. Sociedades multiculturais, interculturalidade e educação. Desafios pedagógicos, comunicacionais e políticos. Revista Portuguesa de Pedagogia, ano 41-3, p. 223-244, 2007.

RAMOS, K.V., FIGUEIRÊDO, A.M.L. Cultura e Turismo: um estudo sobre as trocas interculturais na prática turística. V ENECULT - Encontro de Estudos Multidisciplinares em Cultura. Faculdade de Comunicação/UFBA, Salvador-Bahia, 2009.

SACHS, I. Caminhos para o desenvolvimento sustentável. Tradução de José Lins Albuquerque Filho. 4. Ed. Garamond. Rio de Janeiro, 2002. 
SOGAYAR, R.L.REJOWSKI, M. Ensino superior em turismo em busca de novos paradigmas educacionais: problemas, desafios e forças de pressão. Revista Turismo e Ação - Eletrônica, Vol.13 - no 0, p. 282-289 / set-dez. 2011.

Disponível: www.univali.br/revistaturismo - Acesso em: 19/08/2012.

UNESCO. Investir na diversidade cultural e no diálogo intercultural. Relatório Mundial da Unesco, Cap. I, p. 1-40, Paris: Organização das Nações Unidas para a Educação, a Ciência e a Cultura, 2009. Disponível: http://unesdoc.unesco.org/ images/0018/001847/184755por.pdf. Acesso 19 ago. 2012.

UNESCO. Diversidad Cultural e Interculturalidad en Educación Superior. Experiencias en América Latina. Instituto Internacional de la UNESCO para la Educación Superior en América Latina y el Caribe IESALC-UNESCO, 2008. Disponível: http:// unesdoc.unesco.org/images/0013/001375/137520e. pdf - UNESCO. Perspectiva multiculturalismo. Acesso em: 10 dez. 2011.

UNESCO. "Compromisso de Rabat" sobre o Diálogo de Culturas e Civilizações (Rabat, Marrocos, 14-16 de Junho de 2006). Disponível em: http://www.unesco.org/ dialogue/rabat/commitment.html. Acesso em 08 de Jul.2008.

URRY, J. O olhar do turista: lazer e viagens nas sociedades contemporâneas. São Paulo: Studio Nobel, SESC, 1996.

VIEIRA, R. Ser inter/multicultural. A Página da Educação, N. 78. Ano 8, p.2, Março 1999. http://www.apagina.pt/?aba=7\&cat=78\&doc=7627\&mid=2. Acesso em: 09 de dez. 2011. WALESKO, A.M.H. A interculturalidade no ensino comunicativo de língua estrangeira: um estudo em sala de aula com leitura em inglês. Dissertação (Mestrado em Estudos Linguísticos) - Faculdade de Letras, UFPR, Curitiba, 2006.

WEAVER, D. Sustainable Tourism: Theory and Practice. Oxford: Elsevier ButterworthHeinemann, 2006. 